\title{
Investigation and Research on Student Satisfaction Evaluation of Campus Node Square-Taking Southwest University of Science and Technology as an Example
}

\author{
Jingyuan Yang, Xiaolan Wang* \\ Southwest University of Science and Technology, Mianyang, China \\ Email: ^13980851041@163.com
}

How to cite this paper: Yang, J. Y., \& Wang, X. L. (2021). Investigation and Research on Student Satisfaction Evaluation of Campus Node Square-Taking Southwest University of Science and Technology as an Example. Open Journal of Social Sciences, 9, 385-396.

https://doi.org/10.4236/jss.2021.96026

Received: June 2, 2021

Accepted: June 26, 2021

Published: June 29, 2021

Copyright $\odot 2021$ by author(s) and Scientific Research Publishing Inc. This work is licensed under the Creative Commons Attribution International License (CC BY 4.0).

http://creativecommons.org/licenses/by/4.0/

\section{(c) (i) Open Access}

\begin{abstract}
With the development and maturity of higher education in China, the construction of university campus is also facing many problems, among which the research and design of campus node square cannot be ignored. Aiming at investigating students' satisfaction, this paper establishes a satisfaction evaluation index system. Relevant data of each evaluation index were obtained by questionnaire survey. By means of the fuzzy comprehensive evaluation method, this paper studies the relationship between the perceptual characteristics of four typical campus node squares in Qingyi Campus of Southwest University of Science and Technology and students' satisfaction, which provides a reference for the humanized design of campus node space. The research shows that the four indexes of humanistic atmosphere, interest, ground pavement and atmosphere are the key points in the design and construction of campus node square. The four squares have different shapes. Except for the Light of Science and Technology Square, the satisfaction rate is $67 \%$, and the other three squares are not satisfied by the majority of students. Finally, aiming at the problems of four squares, we put forward to optimize the layout, and improve the infrastructure and functional configuration, etc.
\end{abstract}

\section{Keywords}

Campus Node Square, Satisfaction, Fuzzy Comprehensive Evaluation

\section{Introduction}

Campus square is a public open place serving teachers and students, and is the spiritual core of university campus (Ma, 2005). High quality campus square can improve the quality of life of teachers and students, and students are the main 
body of campus life; therefore, the construction of campus square should be to improve the quality of life of students in the first place, fully pay attention to the needs and feelings of students. In the planning of campus square, it is impossible to grasp all the information, and pure rationality does not exist in practice. Human's decision-making behavior relies on bounded rationality rather than pure rationality, so in the decision-making behavior, the optimal decision-making criterion should be replaced by the satisfying decision-making criterion (Wen, 2009). Is the campus square function layout reasonable? In order to measure the degree of realization of students' interests, a scientific evaluation index system should be established to measure students' satisfaction with campus square. At present, there have been studies on the perception of campus node space and the satisfaction of urban public space. This paper will combine the perception and satisfaction to evaluate the campus node square with human senses as the main body.

\section{Scope and Object of Study}

\subsection{Research Scope}

With the promulgation and implementation of the strategy of "rejuvenating the country through science and education", China's higher education has developed rapidly, and the construction of university campus has also developed rapidly. Campus node space not only contributes to the overall spatial planning and design of the campus, but also carries the function of improving students' physical and mental health and comprehensive quality, reflecting the historical context and the school spirit and appearance of the university, and building the campus personality card. Therefore, the human-oriented campus node space research and design concept is particularly important (Li \& Zhang, 2019).

Taking Southwest University of Science and Technology as an example, this paper studies the node square in its campus.

\subsection{Research Subjects}

Every campus has some form of central square or meeting place, which plays the role of holding meetings, opening exhibitions, holding speeches and so on. It is a large space for students to communicate and communicate. Reasonable design of square space is the main means to improve the communication space of university campus (Zhao \& Li, 2008).

Now, considering the representativeness and operability of the research, four campus node Spaces with different spatial types and scales, namely Colorous Column Square, 107 Square, Wuzhouyuan Square and Light of Science and Technology Square, which are well-known, are selected as the research objects after field investigation, as shown in Figure 1.

\section{Data Sources and Methods}

\subsection{Data Sources}

The survey was taken on-the-spot investigation, questionnaire survey and 


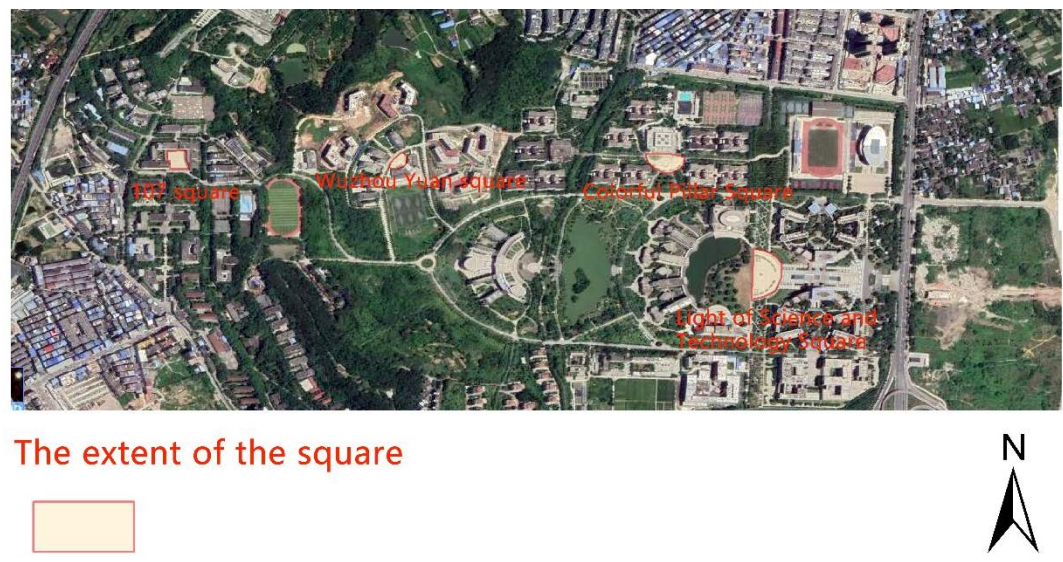

Figure 1. Distribution diagram of object square.

on-the-spot interview method. Questionnaire released in the university undergraduate and graduate students group, survey time for the end of October 2020. Offline 100 questionnaires were issued with 100, 96 copies of effective, effective rate was $96 \%$. Effective recovery of 50 questionnaires online, effective rate was $100 \%$. The questionnaire survey set up four evaluation levels for each index, which were very satisfied, satisfied, average and dissatisfied. The basic information is students' major, grade (undergraduate and graduate), main traffic to and from the square and the distance from the apartment, etc.

A total of 21 questions were designed in the questionnaire. The main content of the questionnaire was the investigation of 17 technical points in the three aspects of the internal space characteristics, space environment and comfort, and space culture of the four nodal squares of Western University of Science and Technology. In his book "The Language of Architectural Patterns", Christopher Alexander sums up his experience with boundary effects and boundary areas in public Spaces: "If boundaries cease to exist, then space will never be alive." (Alexander, 2002) Atmosphere can be viewed as a general impression of an environment, which can be interpreted as beautiful views, good skyline and architectural design, slightly crowded but uninterrupted activities, etc. (Xu, 2006). For open, respectively, as a whole, to the heart of convergence, accessibility, spatial hierarchy, connected-boundary, more or less green landscape, and interesting, atmosphere, vision, ground shop, trademark, culture, because of the characteristics of different objects square, in addition to choose quiet or noisy, boring or rich, rest facilities as a reference index were investigated.

\subsection{Selection of Methods}

In order to better synthesize the evaluation results of qualitative index, this paper chooses the fuzzy comprehensive evaluation method as the comprehensive evaluation tool (Liu, 2012). Make an overall evaluation of things or objects that are subject to multiple factors. It has the characteristics of clear results and strong systematicness. It can better solve fuzzy and difficult to quantify problems, and is suitable for solving various non-deterministic problems. 1) The 
evaluation object is the index in the evaluation index system mentioned above, and the evaluation set $V=$ \{very satisfied, satisfied, ordinary, dissatisfied\}. 2) Determined the evaluation matrix. According to the questionnaire survey, the percentage of residents' opinions on each index in the evaluation set was obtained, and the evaluation matrix $\mathrm{R}$ was obtained by summarizing all indicators. 3) The use of AHP to determine the weight of each evaluation index is mainly the use of expert survey method to determine the weight of each evaluation index in all indicators. 4) The evaluation model is $A=W^{\star} R$, and the percentage of residents' satisfaction with A certain urban public space can be obtained after normalization of the obtained data, which is the result of fuzzy comprehensive evaluation.

\section{Data Processing and Analysis}

\subsection{Results of Questionnaire}

See Tables 1-4 for details.

Table 1. Analysis of the survey results of various indicators of satisfaction of colorful pillar square.

\begin{tabular}{|c|c|c|c|c|c|c|}
\hline & \multicolumn{6}{|c|}{ Spatial characteristics } \\
\hline & Open & $\begin{array}{c}\text { Boundaries } \\
\text { are }\end{array}$ & $\begin{array}{c}\text { To the heart of } \\
\text { convergence }\end{array}$ & Accessibility & $\begin{array}{c}\text { Spatial } \\
\text { hierarchy }\end{array}$ & Item \\
\hline Very satisfied with & 0.30 & 0.15 & 0.20 & 0.30 & 0.25 & 0.20 \\
\hline Satisfactory & 0.40 & 0.40 & 0.40 & 0.35 & 0.15 & 0.55 \\
\hline General & 0.25 & 0.35 & 0.25 & 0.25 & 0.55 & 0.15 \\
\hline Not satisfied with & 0.50 & 0.10 & 0.15 & 0.10 & 0.50 & 0.10 \\
\hline \multicolumn{5}{|c|}{ Space environment and comfort } & \multicolumn{2}{|c|}{ Space culture } \\
\hline Interesting & Ground shop & $\begin{array}{l}\text { Field } \\
\text { of vision }\end{array}$ & Greening & Atmosphere & Iconic & Humanities \\
\hline 0.50 & 0.10 & 0.25 & 0.10 & 0.50 & 0.15 & 0.10 \\
\hline 0.30 & 0.25 & 0.40 & 0.20 & 0.60 & 0.30 & 0.20 \\
\hline 0.50 & 0.55 & 0.30 & 0.50 & 0.30 & 0.35 & 0.55 \\
\hline 0.15 & 0.10 & 0.50 & 0.20 & 0.50 & 0.20 & 0.15 \\
\hline
\end{tabular}

Table 2. Analysis of the survey results of each index of satisfaction of the square.

\begin{tabular}{ccccccc}
\hline \multicolumn{7}{c}{ Spatial characteristics } \\
\hline & open & $\begin{array}{c}\text { Boundaries } \\
\text { are }\end{array}$ & $\begin{array}{c}\text { To the heart of } \\
\text { convergence }\end{array}$ & Accessibility & $\begin{array}{c}\text { Spatial } \\
\text { hierarchy }\end{array}$ & Item \\
\hline Very satisfied with & 0.15 & 0.17 & 0.07 & 0.15 & 0.04 & 0.13 \\
Satisfactory & 0.48 & 0.52 & 0.43 & 0.50 & 0.30 & 0.39 \\
General & 0.35 & 0.26 & 0.43 & 0.30 & 0.52 & 0.41 \\
Not satisfied with & 0.02 & 0.04 & 0.07 & 0.04 & 0.13 & 0.07 \\
\hline
\end{tabular}




\section{Continued}

\begin{tabular}{ccccccc}
\hline \multicolumn{4}{c}{ Space environment and comfort } & & \multicolumn{2}{c}{ Space culture } \\
\hline Interesting & Ground shop & $\begin{array}{c}\text { Field of } \\
\text { vision }\end{array}$ & Greening & Atmosphere & Iconic & Humanities \\
\hline 0.00 & 0.07 & 0.02 & 0.00 & 0.04 & 0.02 & 0.00 \\
0.22 & 0.39 & 0.50 & 0.09 & 0.39 & 0.26 & 0.39 \\
0.50 & 0.41 & 0.39 & 0.37 & 0.50 & 0.43 & 0.46 \\
0.28 & 0.13 & 0.09 & 0.54 & 0.07 & 0.28 & 0.15 \\
\hline
\end{tabular}

Table 3. Analysis of the satisfaction index of Wuzhouyuan plaza.

\begin{tabular}{|c|c|c|c|c|c|c|}
\hline & \multicolumn{6}{|c|}{ Spatial characteristics } \\
\hline & Open & $\begin{array}{c}\text { Boundaries } \\
\text { are }\end{array}$ & $\begin{array}{l}\text { To the heart of } \\
\text { convergence }\end{array}$ & Accessibility & $\begin{array}{c}\text { Spatial } \\
\text { hierarchy }\end{array}$ & Item \\
\hline Very satisfied with & 0.10 & 0.07 & 0.10 & 0.17 & 0.14 & 0.14 \\
\hline Satisfactory & 0.48 & 0.52 & 0.34 & 0.52 & 0.34 & 0.48 \\
\hline General & 0.41 & 0.31 & 0.52 & 0.28 & 0.41 & 0.17 \\
\hline Not satisfied with & 0.00 & 0.10 & 0.03 & 0.03 & 0.10 & 0.21 \\
\hline \multicolumn{5}{|c|}{ Space environment and comfort } & \multicolumn{2}{|c|}{ Space culture } \\
\hline Interesting & Ground shop & $\begin{array}{c}\text { Field of } \\
\text { vision }\end{array}$ & Greening & Atmosphere & Iconic & Humanities \\
\hline 0.07 & 0.10 & 0.21 & 0.14 & 0.07 & 0.10 & 0.07 \\
\hline 0.07 & 0.17 & 0.45 & 0.10 & 0.34 & 0.21 & 0.07 \\
\hline 0.59 & 0.41 & 0.31 & 0.34 & 0.45 & 0.48 & 0.59 \\
\hline 0.28 & 0.31 & 0.03 & 0.41 & 0.14 & 0.21 & 0.28 \\
\hline
\end{tabular}

Table 4. Analysis of the survey results of various indicators of satisfaction of light of science and technology plaza.

\begin{tabular}{|c|c|c|c|c|c|c|}
\hline & \multicolumn{6}{|c|}{ Spatial characteristics } \\
\hline & Open & $\begin{array}{c}\text { Boundaries } \\
\text { are }\end{array}$ & $\begin{array}{l}\text { To the heart of } \\
\text { convergence }\end{array}$ & Accessibility & $\begin{array}{c}\text { Spatial } \\
\text { hierarchy }\end{array}$ & Item \\
\hline Very satisfied with & 0.48 & 0.33 & 0.30 & 0.26 & 0.30 & 0.30 \\
\hline Satisfactory & 0.41 & 0.33 & 0.48 & 0.56 & 0.41 & 0.44 \\
\hline General & 0.11 & 0.33 & 0.22 & 0.15 & 0.26 & 0.26 \\
\hline Not satisfied with & 0.00 & 0.00 & 0.00 & 0.04 & 0.04 & 0.00 \\
\hline \multicolumn{5}{|c|}{ Space environment and comfort } & \multicolumn{2}{|c|}{ Space culture } \\
\hline Interesting & Ground shop & $\begin{array}{l}\text { Field of } \\
\text { vision }\end{array}$ & Greening & Atmosphere & Iconic & Humanities \\
\hline 0.11 & 0.19 & 0.33 & 0.11 & 0.26 & 0.26 & 0.15 \\
\hline 0.41 & 0.52 & 0.52 & 0.48 & 0.41 & 0.59 & 0.52 \\
\hline 0.41 & 0.22 & 0.15 & 0.26 & 0.33 & 0.11 & 0.30 \\
\hline 0.07 & 0.07 & 0.00 & 0.15 & 0.00 & 0.04 & 0.04 \\
\hline
\end{tabular}




\subsection{Determine the Evaluation Object and Evaluation Set}

The evaluation object is the index in the above evaluation index system, and the evaluation set $V=\{$ very satisfied, satisfied, ordinary, dissatisfied $\}$.

\subsection{Determine the Evaluation Matrix}

According to the questionnaire survey to get satisfied with the percentage of each index in the evaluation set as $R_{1}=\{0.3,0.4,0.25,0.05\}$ says to the first index are obtained by questionnaire, "very satisfied" crowd people accounted for $30 \%$, "satisfaction" 40\%, and 25\%, "generally" people "not satisfied" (5\%) collect all indicators evaluation matrix $R_{A}=\left\{R_{1}, R_{2} \ldots R_{17}\right\}^{T}$ And the same thing goes for $R_{B}$, $\mathrm{R}_{\mathrm{C}}, \mathrm{R}_{\mathrm{D}}$. According to the questionnaire data, it can be seen that:

\begin{tabular}{|c|c|c|c|c|c|c|c|c|c|c|c|c|c|c|}
\hline \multirow{4}{*}{$\mathrm{R}_{\mathrm{A}}=-$} & 0.30 & 0.15 & 0.20 & 0.30 & 0.25 & 0.20 & 0.50 & 0.10 & 0.25 & 0.10 & 0.50 & 0.15 & 0.10 & \multirow{4}{*}{$-\mathrm{T}$} \\
\hline & 0.40 & 0.40 & 0.40 & 0.35 & 0.15 & 0.55 & 0.30 & 0.25 & 0.40 & 0.20 & 0.60 & 0.30 & 0.20 & \\
\hline & 0.25 & 0.35 & 0.25 & 0.25 & 0.55 & 0.15 & 0.50 & 0.55 & 0.30 & 0.50 & 0.30 & 0.35 & 0.55 & \\
\hline & 0.50 & 0.10 & 0.15 & 0.10 & 0.50 & 0.10 & 0.15 & 0.10 & 0.50 & 0.20 & 0.50 & 0.20 & 0.15 & \\
\hline \multirow{4}{*}{ 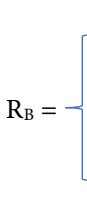 } & 0.15 & 0.17 & 0.07 & 0.15 & 0.04 & 0.13 & 0.00 & 0.07 & 0.02 & 0.00 & 0.04 & 0.02 & 0.00 & \multirow{4}{*}{$-\mathrm{T}$} \\
\hline & 0.48 & 0.52 & 0.43 & 0.50 & 0.30 & 0.39 & 0.22 & 0.39 & 0.50 & 0.09 & 0.39 & 0.26 & 0.39 & \\
\hline & 0.35 & 0.26 & 0.43 & 0.30 & 0.52 & 0.41 & 0.50 & 0.41 & 0.39 & 0.37 & 0.50 & 0.43 & 0.46 & \\
\hline & 0.02 & 0.04 & 0.07 & 0.04 & 0.13 & 0.07 & 0.28 & 0.13 & 0.09 & 0.54 & 0.07 & 0.28 & 0.15 & \\
\hline \multirow{4}{*}{$\mathrm{R}_{\mathrm{C}}=\{$} & 0.10 & 0.07 & 0.10 & 0.17 & 0.14 & 0.14 & 0.07 & 0.10 & 0.21 & 0.14 & 0.07 & 0.10 & 0.10 & \multirow{4}{*}{$-\mathrm{T}$} \\
\hline & 0.48 & 0.52 & 0.34 & 0.52 & 0.34 & 0.48 & 0.07 & 0.17 & 0.45 & 0.10 & 0.34 & 0.21 & 0.14 & \\
\hline & 0.41 & 0.31 & 0.52 & 0.28 & 0.41 & 0.17 & 0.59 & 0.41 & 0.31 & 0.34 & 0.45 & 0.48 & 0.59 & \\
\hline & 0.00 & 0.10 & 0.03 & 0.03 & 0.10 & 0.21 & 0.28 & 0.31 & 0.03 & 0.41 & 0.14 & 0.21 & 0.17 & \\
\hline \multirow{4}{*}{$\mathrm{R}_{\mathrm{D}}=\{$} & 0.48 & 0.33 & 0.30 & 0.26 & 0.30 & 0.30 & 0.11 & 0.19 & 0.33 & 0.11 & 0.26 & 0.26 & 0.15 & \multirow{4}{*}{$-\mathrm{T}$} \\
\hline & 0.41 & 0.33 & 0.48 & 0.56 & 0.41 & 0.44 & 0.41 & 0.52 & 0.52 & 0.48 & 0.41 & 0.59 & 0.52 & \\
\hline & 0.11 & 0.33 & 0.22 & 0.15 & 0.26 & 0.26 & 0.41 & 0.22 & 0.15 & 0.26 & 0.33 & 0.11 & 0.30 & \\
\hline & 0.00 & 0.00 & 0.00 & 0.04 & 0.04 & 0.00 & 0.07 & 0.07 & 0.00 & 0.15 & 0.00 & 0.04 & 0.04 & \\
\hline
\end{tabular}

\subsection{Use Analytic Hierarchy Process to Determine the Weight of Each Index}

1) Judgment matrix scale

The weight is determined by the experts to fill in the form to finally determine the importance of each factor. The scale of the matrix scale is judged by the importance of each index (Table 5), so as to determine the judgment matrix. This process is determined by majority principle.

According to the uniform design principle of matrix scale, $I, j(I, j=1,2, \ldots, n)$ are used respectively to represent an element of the survey item. The value of the judgment matrix reflects people's understanding of the relative importance of each factor. Generally, the 1 - 7 scale is used to assign the importance degree. For example, if the majority of experts' choices focus on " $I$ is slightly more important 
Table 5. Judgment matrix scale.

\begin{tabular}{cll}
\hline The serial number & \multicolumn{1}{c}{ Level of importance } \\
\hline 1 & The $I$ and $j$ elements are equally important & 1 \\
3 & The $I$ element is slightly more important than the $j$ element & 3 \\
4 & The $I$ element is significantly more important than the $j$ element & 5 \\
5 & The $I$ element is more important than the $j$ element $I$ element is slightly less important than the $j$ element & $1 / 3$ \\
6 & The $I$ element is obviously less important than the $j$ element & $1 / 5$ \\
7 & It doesn't matter that the $I$ element is stronger than the $j$ element & $1 / 7$ \\
\hline
\end{tabular}

than $"$, fill in 3 at the appropriate position in the corresponding judgment matrix. The final judgment matrix is obtained by determining each digit in the judgment matrix.

2) Consistency test

Consistency check refers to the consistency check of the judgment matrix. Due to the complexity and diversity of people's judgment of objective things, the judgment matrix often appears inconsistent phenomenon, therefore, it is necessary to carry out the consistency test of the judgment matrix, so that the results are accurate. Find the maximum eigenvalues of each judgment matrix, and then use the following formula to calculate: $C i=\left(\lambda_{\max }-n\right) /(n-1)$. In the formula, the larger the $C I$ value is, the worse the consistency of the judgment matrix is. The smaller $C I$ value is, the better the consistency of judgment matrix is (Table 6).

According to the consistency test, the consistency ratio is as follows: when $C R$ $=C i / R i<0.10$, the judgment matrix is considered to have satisfactory consistency; otherwise, the judgment matrix needs to be adjusted to make it have satisfactory consistency. The value of $R I$ is related to the order of the judgment matrix, and its value is shown in Table 6. MATLAB software is used to calculate the maximum eigenvalue of the judgment matrix and its corresponding eigenvector, and its eigenvector is normalized to get the weight. Finally, the weight of the first-level index is multiplied by the weight of the second-level index to get the final weight of each evaluation index W. In this paper, the first level indicators are natural environment, human environment, supporting facilities, management services; the two-level index is each index below one-level index. The weights of first-level indicators and second-level indicators were obtained by analytic hierarchy process. Finally, the final weights of second-level indicators were obtained by multiplying the weights of first-level indicators and second-level indicators:

$W=\{0.004,0.003,0.029,0.010,0.016,0.012,0.194,0.135,0.110,0.088,0.116$, $0.035,0.247\}$

The indexes with the highest weight value are humanistic atmosphere, interest, ground pavement and atmosphere in turn. This indicates that these indicators should be the key points in the design and construction of campus node square. 
Table 6. Average random consistency test.

\begin{tabular}{ccccccccc}
\hline 1 & 2 & 3 & 4 & 5 & 6 & 7 & 8 & 9 \\
\hline 0.00 & 0.00 & 0.58 & 0.90 & 1.12 & 1.24 & 1.32 & 1.41 & 1.45 \\
\hline
\end{tabular}

\subsection{Comprehensive Evaluation and Analysis}

Comprehensive evaluation analysis uses evaluation model $A_{1}=R_{A}{ }^{\star} W=\{0.2516$, $0.301,0.4536,0.234\}$ to calculate the results. The results were calculated. Normalize the evaluation results, that is, divide each number in the matrix $A_{1}$ by the sum of all the numbers, calculate the percentage of each part, and get the matrix: $A_{1}^{\prime}=\{0.20,0.25,0.36,0.19\}$. According to the evaluation results, $20 \%$ people are "very satisfied" with all the indicators of Colorful Pillars Square, 25\% are "satisfied", $36 \%$ are "general" and 19\% are "not satisfied". Based on the data of "very satisfied" and "satisfied", the degree of satisfaction for Colorful Pillar Square is $45 \%$. Similarly, we can get:

$$
A_{2}=R_{B}{ }^{\star} W=\{0.1080,0.2059,0.4776,0.2067\}, A_{2}^{\prime}=\{0.11,0.21,0.48,0.21\} \text {. }
$$

According to the evaluation results, 11 percent of people are "very satisfied", 21 percent are "satisfied", 48 percent are "general" and 21 percent are "not satisfied". Based on the data of "very satisfied" and "satisfied", the students' satisfaction with Wuzhou Yuan Plaza is $32 \%$.

$$
A_{3}=R_{C}{ }^{\star} W=\{0.0238,0.3394,0.4454,0.1898\}, A_{3}^{\prime}=\{0.02,0.34,0.45,0.19\} \text {. }
$$

According to the evaluation results, $2 \%$ of people are "very satisfied", $34 \%$ are "satisfied", $45 \%$ are "general" and 19\% are "not satisfied". Combining the data of "very satisfied" and "satisfied", students' satisfaction with 107 Plaza is $36 \%$.

$A_{4}=R_{D}{ }^{*} W=\{0.1919,0.4798,0.2814,0.0486\}, A_{4}^{\prime}=\{0.19,0.48,0.28,0.05\}$. According to the evaluation results, $19 \%$ of people are "very satisfied", $48 \%$ are "satisfied", 28\% are "general" and 5\% are "not satisfied". Combining the data of "very satisfied" and "satisfied", students' satisfaction with Light of Science and Technology Square is 67\%.

\section{Comparison and Analysis of Satisfaction Difference of Different Node Squares}

The four plazas have different geographical locations, different forms of space enclosure and different functions. Now a horizontal comparison of the satisfaction of the four plazas is made, as shown in Figure 2.

It can be seen that the degree of satisfaction of Light of Science and Technology Square is the highest (67\%), followed by Colorful-column Square (45\%), 107 Square and Wuzhouyuan Square are lower, respectively $36 \%$ and $32 \%$. In addition to the Light of Science and Technology Square, the dissatisfaction rates of the other three squares are all around $20 \%$, with the majority of people believing that ordinary people are in the majority. Colorful column square is very well connected, and rest facilities are few. The boundary of 107 square feels good, but there are basically no greening and rest facilities. The accessibility of Wuzhou 


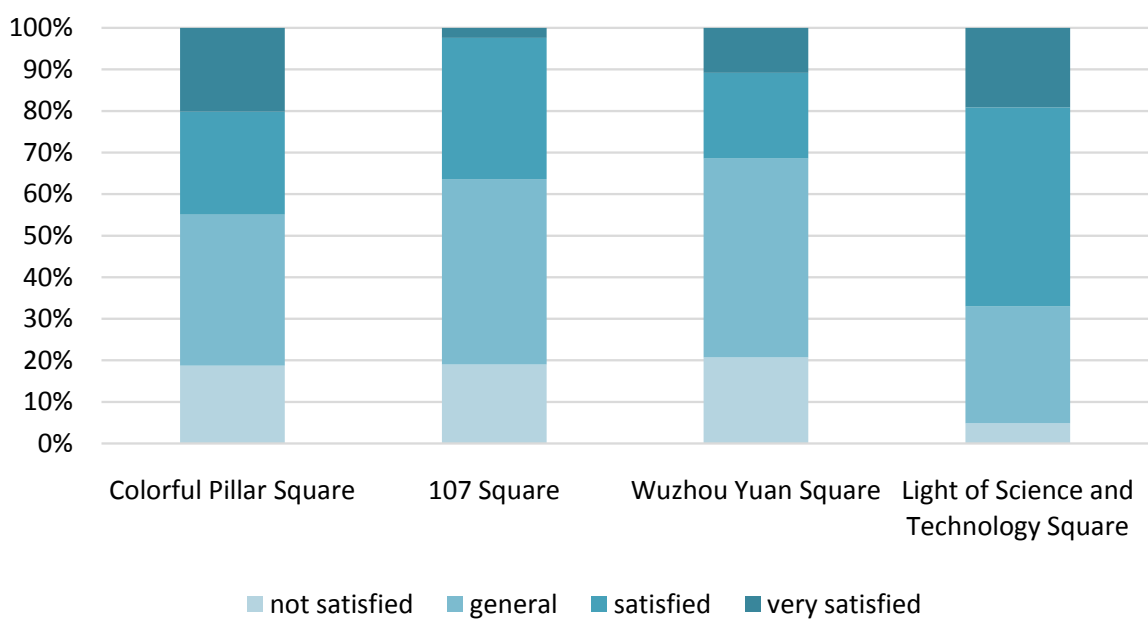

Figure 2. Comparison of satisfaction of four squares.

Garden Square is good, but it is monotonous and less green. The openness of Light of Science and Technology Square is good, but the atmosphere is not good. The following will analyze these squares respectively and give advice.

\subsection{Colorful Pillars Square}

Located in the new area of Xi'an University of Science and Technology, it is a sunken square surrounded by five canteens and dormitory buildings on three sides (Figure 3(A)). The main opening faces the teaching building on one side of the main road. Therefore, the main service objects of the square are students who come to the canteen to eat and students who come to the square to rest and play in their spare time. In terms of spatial characteristics, its openness, centripetal convergence, accessibility and connection have been recognized by many people, and there are multiple roads leading to the square in the surrounding buildings. In terms of space environment and comfort, $55 \%$ of people think the pavement on the ground is general, indicating that the pavement needs to be improved. Part of the reason is that during the peak period of class, the flow of students is huge, which causes great damage to the main passageway. Therefore, it is suggested to widen the passageway facing the side of the teaching building and remove the green belt that restricts the passage of students. The results of the questionnaire survey show that the atmosphere of the square is recognized by students. Students often play skateboards here, or sit on the steps to talk. The square also has places for school activities, temporary sales of small goods, and a small store next to it, which is convenient for students' daily shopping needs. In addition, as a reference index of rest facilities, the dissatisfaction rate is up to $55 \%$. Although the grass altar on the square can allow students to sit down and rest, its comfort level is completely inadequate and needs to be strengthened. In terms of space culture, the humanistic atmosphere still needs to be strengthened. The LED screen on the square can be fully utilized to play political and school-related videos, notice and publicity, etc. 


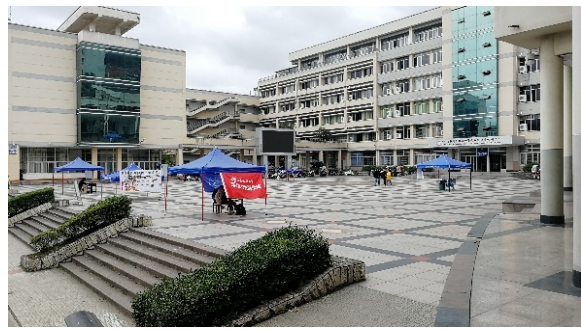

(A)

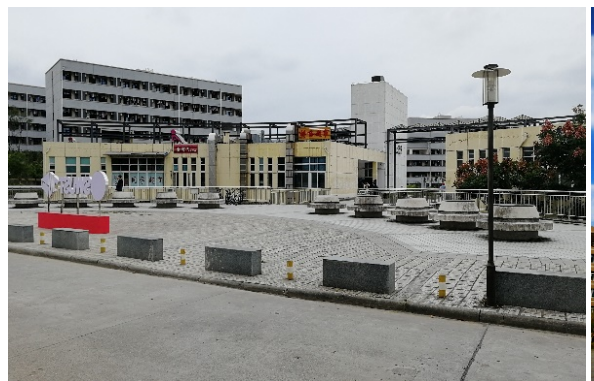

(C)

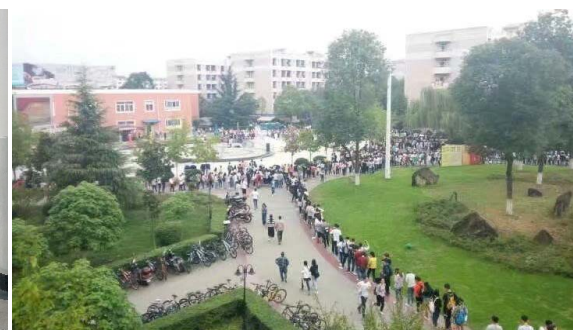

(B)

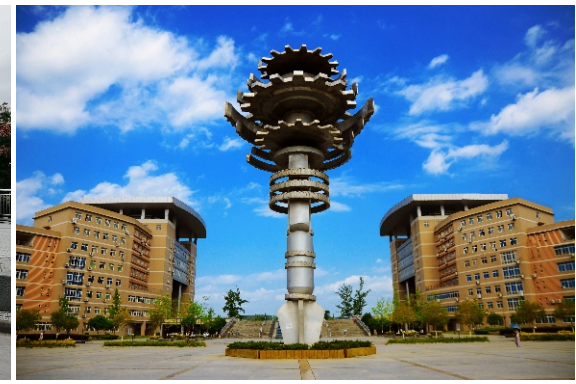

(D)

Figure 3. Real view of each node square. (A) 107 Square; (B) Colorful Pillar Square; (C) Wuzhou Yuan Square; (D) Light of Science and Technology Square.

\subsubsection{Square}

Located in the old area of Western University of Science and Technology, it is a square surrounded by three teaching buildings of West 7 (Figure 3(B)). The opposite side is the starting station of campus bus buns and the landscape and waterscape green space. The places farther away are all dormitory buildings. Therefore, the square is a gathering place for students to attend classes, a venue for school gatherings and a place for students to entertain after class. In terms of spatial characteristics, the satisfaction of the six indicators is very high, except for the sense of hierarchy and connection. This is because the square is attached to the teaching building, and it is very flat except that there are several steps connected to the square plane. In terms of the space environment and comfort of the square, the majority of people think that the pavement on the ground is ordinary or unsatisfactory. This is because it is rainy in Mianyang, the pavement has no permeability, and the ground is easy to water and slippery, which brings inconvenience to students. In terms of space culture, many students are not satisfied with the symbol. Since the school stipulates that the square has the function of gathering, landscape skits and landmark structures are not allowed. However, the facade of the teaching building can be beautified to meet the needs of increasing space culture.

\subsection{Wuzhou Yuan Square}

The roof of Wuzhou Yuan canteen in the central district is a unique construction method in the mountainous and hilly terrain (Figure $3(\mathrm{C})$ ). The square is on the same level with the road in front of the dormitory building and the second floor of the canteen. On the other side of the square, there are steps to go 
down to the door of the first floor of the canteen. Opposite the dining hall is a court. The square is mainly used for students' leisure and entertainment. In terms of spatial characteristics, many people are not satisfied with the spatial level, connection and boundary sense. This is because in order to prevent vehicles from parking in the square, several large squares are set up on the boundary of the square, which makes it very ugly and inconvenient. In terms of space environment and comfort, the square scores high in the field of vision, but other indicators of satisfaction are very poor, monotonous, lack of entertainment environment, no greening, and poor pavement. It is suggested to plant more trees in it, add some rest facilities, remove the large block and improve the pavement. Space culture also needs to be strengthened.

\subsection{Light of Science and Technology Square}

It is located in the new district, close to the school gate, with the staff canteen and four college buildings on one side, and the artificial lake green space in front of the administrative building on the other side, with a road divided horizontally (Figure 3(D)). Its main function is the gathering and distribution of the crowd. In terms of spatial features, satisfaction was high, except for accessibility. There were a few people who were not satisfied because of the limitations of its geographical location. In terms of space environment and comfort, the dissatisfaction with fun, ground pavement, especially rest facilities is relatively high, so it is suggested to place some benches. In terms of space culture, it was generally recognized by the students, and the iconic statue in the center of the square added luster to it.

\section{Conclusion}

This paper embarks from the students' perception and uses requirements of the square, through establishing the satisfaction evaluation index system, using the analytic hierarchy process and fuzzy comprehensive evaluation method to evaluate node square campus. It is concluded that the space environment should be improved, comfort level increased and the space strategy of culture enhanced, expecting to provide a scientific basis for the quality of the square at general colleges and universities. As a talent of education high quality base, Southwest University of Science and Technology Education should penetrate the outdoor space, including square. Campus square of nodes is an important place for teachers and students to improve the life quality of the leisure entertainment, and is also the campus space of the landmark; its spirit is greater than the material meaning. Campus node square is an important place for teachers and students to entertain and improve the quality of life. It is also a landmark space on campus. There are three reasons for the problems existing in the campus square. First, the construction quality is not high due to the short period of campus construction; Second, the improper management after the completion of the campus caused by the use of inconvenience; The third is the incongruity of the relationship with the users (teachers and students in colleges and universities), that is, 
the question of which is the main body of the design, "space" or "people", which is determined by the design strategy and is also the focus of the designer's research (Xie et al., 2012).

Of course, there are some limitations in the study. First, the selection of object indicators affects the progress of correlation analysis to a certain extent, which is embodied in the differences of the evaluators' understanding and cognition of the indicators. There are many object indicators in the square space, so the selection is subjective. Second, the subjective perception of the evaluators is influenced by multiple factors. The test survey in the study is an attempt with a small sample size, which is insufficient to clarify all the characteristics of the four square Spaces. Thirdly, some object indicators have a low influence weight on satisfaction in this study, and the reasons need to be further analyzed. Fourthly, the study does not present the quantitative influence relationship between the relevant object indicators, which needs to be further discussed according to the actual situation and requirements in the concrete practical application.

\section{Conflicts of Interest}

The authors declare no conflicts of interest regarding the publication of this paper.

\section{References}

Alexander, C. (2002). Architectural Pattern Language. Beijing: Intellectual Property Publishing House.

Li, Y., \& Zhang, Y. (2019). Research on the Spatial Perception of Campus Nodes Based on SD Method-A Case Study of Xiamen University. Urban Architecture, 16, 23-28.

Liu, L. (2012). Evaluation Index and Analysis of Residents' Satisfaction in Urban Public Space. Urban Problems, No. 7, 65-68+72.

Ma, M. (2005). Research on Communication Space Design of Universities. Xi'an: Xi'an University of Architecture and Technology.

Wen, Q. (2009). On the Paraegm Evolution of Urban Green Open Space Planning. Chinese Landscape Architecture, 25, 11-14.

Xie, H., Chen, G., \& Wang, F. (2012). "Human-Oriented” Open Space Design of University Campus. Journal of Shenyang Jianzhu University (Social Science Edition), 14, 12-15.

Xu, L. (2006). Research on Spatial Cognition and Satisfaction of Square. Journal of Tongji University (Natural Science Edition), No. 2, 181-185.

Zhao, W., \& Li, D. (2008). Investigation and Analysis of Public Communication Space on University Campus. Northern Horticulture, No. 6, 141-143. 